Gut, 1983, 24, 42-48

\title{
Copper chelation therapy in intrahepatic cholestasis of childhood
}

\author{
J EVANS, * H ZERPA, L NUTTALL, M BOSS, and S SHERLOCK \\ From the Departments of Medicine, Histopathology, and Medical Physics, Royal Free Hospital, London
}

SUMmARY The effect of copper chelation was studied in a group of children with intrahepatic cholestasis of childhood (IHCC) , and increased liver copper levels. Initial therapy was D-penicillamine $(10 \mathrm{mg} / \mathrm{kg} /$ day $)$, being replaced by triethylenetetramine dihydrochloride (20 $\mathrm{mg} / \mathrm{kg} /$ day) when side-effects of D-penicillamine occurred. Eight children completed two years of copper chelation. Pruritis remained the main symptom and did not improve. Two patients developed D-penicillamine side-effects - one patient after nine months (marked anorexia, lassitude) and one other patient after 19 months (thrombocytopenia). Two patients died during the study, in one of these normal hepatic copper concentration was achieved. Hepatic copper concentrations decreased in seven of eight patients from $8.6(2 \cdot 7-16 \cdot 2) \mu \mathrm{mol} / \mathrm{g}$ to $3.4(0 \cdot 6-16 \cdot 5)$ $\mu \mathrm{mol} / \mathrm{g}$ (median and range $(0.05<\mathrm{p}<0.1)$ and serum aspartate transaminase increased in seven of eight patients $(p<0 \cdot 05)$. Histological assessment of serial liver sections revealed increased fibrosis and cholestasis despite reductions in hepatic copper levels during the study. This study showed that D-penicillamine therapy was associated with significant side-effects, while marked clinical, biochemical, or histological improvement did not follow effective copper chelation therapy in intrahepatic cholestasis of childhood.

The liver is the principal organ involved in copper metabolism. ${ }^{1}$ It is the main site of copper storage as well as the organ in which caeruloplasmin is synthesised. ${ }^{2}$ Normal liver copper levels are maintained by excretion of copper into bile or incorporation of copper into caeruloplasmin and secretion into plasma. Normally, about $80 \%$ of copper absorbed from the diet is excreted into bile. ${ }^{3}$ An impairment of hepatic copper excretion is likely to be associated with increased hepatic copper concentrations.

Abnormal accumulation of copper in the liver $(>4$ $\mu \mathrm{mol} / \mathrm{g}$ dry weight), brain, and kidney in Wilson's disease is associated with tissue damage ${ }^{4}$ and $D$ penicillamine therapy effects clinical improvement. ${ }^{5}$ Copper hepatocytotoxicity may also develop with copper sulphate poisoning in $\operatorname{man}^{6}$ and in experimental animals. ${ }^{7}$ Liver copper concentration exceeding $4 \mu \mathrm{mol} / \mathrm{g}$ has been described with chronic cholestasis associated with primary biliary cirrhosis, ${ }^{8-13}$ intrahepatic cholestasis of childhood

\footnotetext{
- Address for correspondence: Dr J Evans, Department of Paediatric Gastroenterology, Mater Children's Hospital, South Brisbane, 4101, Queensland, Australia.

Received for publication 13 April 1982
}

(IHCC), ${ }^{14}{ }^{15}$ extrahepatic biliary obstruction, ${ }^{16}$ and Indian childhood cirrhosis. ${ }^{17}$ Increased liver copper concentration may contribute to continuing hepatic necrosis in primary biliary cirrhosis and Dpenicillamine therapy effects histological ${ }^{10}$ and biochemical $^{18}$ improvement. This beneficial result of D-penicillamine therapy in primary biliary cirrhosis may be related to an immunological effect or copper chelation. ${ }^{18}$

Intrahepatic cholestasis of childhood is a rare disorder, usually of unknown aetiology, in which immunological mechanisms do not appear prominent in the pathogenesis of the disorder. ${ }^{19}$ Life expectancy is reduced, therapy is symptomatic, and liver cell failure is a common mode of death. ${ }^{19}$ High liver copper levels, which might contribute to continuing hepatic necrosis, are common ${ }^{14}{ }^{15}$ and tend to occur in older children. ${ }^{15}$ By analogy with Wilson's disease and primary biliary cirrhosis a trial of D-penicillamine therapy in selected patients with intrahepatic cholestasis of childhood appeared warranted. We report the clinical, biochemical, and histological effect of copper chelation therapy in a non-immunological chronic cholestatic disorder of childhood with increased hepatic copper levels. 


\section{Methods}

\section{PATIENTS}

Eight children with intrahepatic cholestasis of childhood and raised hepatic copper levels were studied. Diagnosis was based on clinical, biochemical, and histological evidence. ${ }^{19}$ Extrahepatic biliary obstruction was excluded by laparotomy (four cases) or by ultrasound examination and percutaneous transhepatic cholangiography (four cases). Seven cases were sporadic, while the eighth case had a brother with intrahepatic cholestasis of childhood who had died earlier after haemorrhage from oesophageal varices. Pulmonary flow murmurs were present in two children; one of these, in addition, had congenital glaucoma. In these two cases there was no evidence of pulmonary valve stenosis as assessed clinically, with ECG, radiograph of the chest, or echocardiography. Arteriography was not performed. On entry to the study all cases were negative for $\mathrm{HBsAg}$, anti-HBs, and anti-HBc and had normal levels of serum alpha-1-antitrypsin. Children with characteristic facies and cardiac lesions, ${ }^{20}$ Byler's syndrome, ${ }^{21}$ or arteriohepatic dysplasia $^{22}$ were not present in this series. The patients were of various nationalities: Arabian, one; Italian, one; Portuguese, one; Greek, two; English, three. This group was composed of five females and three males. The ages of children in the group ranged from 2 years to 22 years and the median age was 7 years. None had had portal-systemic shunt surgery.

\section{PROTOCOL}

Treatment with D-penicillamine was started at a dose of $5 \mathrm{mg} / \mathrm{kg} /$ day and increased to $10 \mathrm{mg} / \mathrm{kg} /$ day after two months in the hope of minimising the incidence of side-effects. D-penicillamine was prescribed as a single dose, to be taken each morning on an empty stomach 30 minutes before the other medication or meals. Triethylenetetramine dihydrochloride $(20 \mathrm{mg} / \mathrm{kg} /$ day $)$, another cupruretic agent, ${ }^{23}$ was substituted when side-effects to Dpenicillamine occurred. Approval for copper chelation therapy in intrahepatic cholestasis of childhood, on a trial basis, was obtained from the Department of Health and Social Services and the conduct of the study was approved by the Ethics Committee of the Royal Free Hospital. Informed consent was obtained from the parents before entering each patient into the study and before each liver biopsy.

Before initiating copper chelating therapy in each patient, a clinical history was obtained with particular reference to the major symptom; daily intake of cholestyramine was noted; the height and weight of each patient was recorded; liver function tests (bilirubin, aspartate transaminase, alkaline phosphatase) and fasting bile acids were performed. ${ }^{24}$ As well, copper metabolism was studied in general with plasma caeruloplasmin and copper, 24 hour urinary copper excretion and liver copper concentration before the start of therapy. A measure of circulating immune complexes was made with the $C_{1 q}$ binding assay. ${ }^{25}$ The above investigations were repeated at annual visits.

\section{PROCEDURE}

Liver function tests were determined by routine methods. Total plasma copper and 24 hour urinary copper excretion were determined by atomic absorption spectroscopy. ${ }^{26}$ Normal values are 15 to $22 \mu \mathrm{mol} / /(100-140 \mu \mathrm{g} / 100 \mathrm{ml})$ and $<0.8 \mu \mathrm{mol} / 24 \mathrm{~h}$ $(<50 \mu \mathrm{g} / 24 \mathrm{~h})$ respectively. The 24 hour urinary copper excretion was the mean of three consecutive 24 hour urine collections obtained in prepared plastic containers. Caeruloplasmin was measured by immunodiffusion and normal values are $0.25-0.4 \mathrm{~g} / 1$. Fasting bile acids were measured by the method of Murphy. ${ }^{24}$

Each liver biopsy was obtained with a Menghini needle which had been rendered copper free. The biopsy needle was washed with a $1 \%$ solution of ethylenediamine tetraacetic acid (EDTA), rinsed with ion-free water, and sterilised in similarly prepared glass containers. A portion of each liver biopsy was obtained for copper concentration and the remaining portion was examined histologically. The copper concentration was measured by neutron activation analysis. ${ }^{27}$ Normal hepatic copper concentration is 0.2 to $0.9 \mu \mathrm{mol} / \mathrm{g}(15-55 \mu \mathrm{g} / \mathrm{g})$ dry liver. The coefficient of variation for duplicate measurements of liver copper levels measured by neutron activation analysis is $7 \%$ to $15 \%$.

\section{$C_{1 q}$ binding}

The effect of D-penicillamine on immune complexes was monitored by the modified $\mathrm{C}_{1 \mathrm{q}}$ binding test which detects immune complexes of greater than $20 \mathrm{~s}$ in size. ${ }^{25}$

\section{Histological assessment}

All the liver biopsies were reviewed ( $\mathrm{HZ}$ and JE) at the end of the study without knowledge of results of biochemical tests or measured liver copper concentrations. Each biopsy was examined with routine histological stains ( $\mathrm{H}$ and $\mathrm{E}$, and reticulin) and with histochemical stains for copper ${ }^{28}$ and copper associated protein. ${ }^{29}$ The histological features of inflammation, necrosis, cholestasis, and fibrosis were specifically semi-quantitatively assessed and graded,,++++++ , for mild, moderate, and 
severe changes. In each biopsy at least 12 portal tracts were viewed and bile ducts counted. Bile duct paucity was considered if there were less than four bile ducts counted in these portal tracts, and bile ducts were absent if none was counted.

\section{Statistical methods}

The paired $t$ test was used for statistical analysis of values of hepatic copper concentration, plasma copper and caeruloplasmin values, 24 hour urine copper excretion, liver function tests, and fasting bile acids before and after copper chelation therapy.

The mean score of standard deviations was used to analyse the effect of therapy on each patient's height and weight. ${ }^{30}$

\section{Results}

\section{CLINICAL}

Marked symptomatic improvement was not observed. Pruritis remained the major symptom and was unchanged during the study period. Two patients developed significant side-effects with Dpenicillamine therapy. One patient developed marked anorexia and lassitude after nine months. Triethylenetetramine dihydrochloride $(20 \mathrm{mg} / \mathrm{kg}$ ) day) was substituted and continued for 15 months without side-effects. The other patient developed significant thrombocytopenia after 19 months of D-penicillamine therapy and declined further copper chelating treatment. Two patients died during the study. One patient died while overseas from a massive gastrointestinal haemorrhage after two years of D-penicillamine therapy, the liver copper concentration just before death was normal. The other patient died from a combination of liver cell failure and repeated gastrointestinal haemorrhages. This patient had received 19 months of D-penicillamine therapy. Hepatic tissue from this patient was obtained at necropsy.

Children entering the study were slightly undersized and underweight. After copper chelation therapy a spurt in height and weight was not observed, despite major falls in hepatic copper concentration in the patients.

\section{LIVER FUNCTION TESTS (Table 1)}

There was no consistent effect of therapy on plasma bilirubin levels. One patient, in whom normal hepatic copper concentration was observed after two years of therapy, demonstrated the largest rise in plasma bilirubin of the group. Aspartate transaminase levels increased in seven of eight patients after two years of copper chelating therapy $(p<0.05)$. This increase in serum aspartate transaminase occurred even if hepatic copper levels decreased into the normal range. Levels of alkaline phosphatase and fasting bile acids were not significantly affected by treatment.

\section{COPPER METABOLISM (Table 2)}

D-penicillamine treatment produced a prompt cupruresis $(0.01<p<0.025)$ but after two years of copper chelation therapy this response was less marked $(0.05<p<0 \cdot 1)$. Hepatic copper concentrations were reduced in seven of eight patients from $8.6(2.7-16.2) \mu \mathrm{mol} / \mathrm{g}$ to $3.4(0.6-16.5) \mu \mathrm{mol} / \mathrm{g}$ (median and range) $(0.05<\mathrm{p}<0.1)$ (Figure). After the trial, normal hepatic copper concentrations were observed in three patients. Cupruresis induced by D-penicillamine therapy did not correlate with the change in hepatic copper concentrations noted in the study. Chelation therapy had no significant effect on plasma copper or caeruloplasmin values.

Table 1 Liver function tests, fasting bile acids, and $C_{1 q}$ parameters in intrahepatic cholestasis of childhood

\begin{tabular}{|c|c|c|c|c|c|c|c|c|c|c|}
\hline \multirow[b]{2}{*}{ Patient } & \multicolumn{2}{|c|}{$\begin{array}{l}\text { Bilirubin } \\
\text { ( } \mu \text { molll) }\end{array}$} & \multicolumn{2}{|c|}{$\begin{array}{l}A S T \\
(U / l)\end{array}$} & \multicolumn{2}{|c|}{$\begin{array}{l}S A P \\
(K A U)\end{array}$} & \multicolumn{2}{|c|}{$\begin{array}{l}\text { Bile acids } \\
\text { ( } \mu \text { molll) }\end{array}$} & \multicolumn{2}{|l|}{$\begin{array}{l}C_{1 q} \\
(\%)\end{array}$} \\
\hline & Pre & Post & Pre & Post & Pre & Post & Pre & Post & Pre & Post \\
\hline 1 & 207 & 390 & 146 & 270 & 90 & 95 & 70 & - & $4 \cdot 3$ & $5 \cdot 4$ \\
\hline 2 & 85 & 101 & 131 & 157 & 108 & 117 & 71 & 49 & - & - \\
\hline 3 & 53 & 48 & 58 & 104 & 37 & 52 & 76 & 80 & $10 \cdot 0$ & $13 \cdot 3$ \\
\hline 4 & 139 & 105 & 78 & 61 & 103 & 66 & 73 & - & - & - \\
\hline 5 & 18 & 31 & 63 & 78 & 80 & 80 & 43 & 28 & 8.9 & $16 \cdot 5$ \\
\hline 6 & 25 & 25 & 15 & 53 & 54 & 65 & 65 & 45 & 2.9 & $13 \cdot 2$ \\
\hline 7 & 78 & 237 & 61 & 212 & 72 & 55 & 79 & - & $13 \cdot 2$ & 14.8 \\
\hline 8 & 42 & 402 & 30 & 45 & 43 & 20 & - & - & - & - \\
\hline $\begin{array}{l}\text { p value } \\
\text { Normal range }\end{array}$ & \multicolumn{2}{|c|}{$\begin{array}{l}\text { NS } \\
2-17\end{array}$} & \multicolumn{2}{|c|}{$\begin{array}{l}<0.05 \\
15-42\end{array}$} & \multicolumn{2}{|c|}{$\begin{array}{l}\text { NS } \\
3-13\end{array}$} & \multicolumn{2}{|c|}{$\begin{array}{l}\text { NS } \\
\leqslant 15\end{array}$} & \multicolumn{2}{|c|}{$\begin{array}{l}\text { NS } \\
\leqslant 10\end{array}$} \\
\hline
\end{tabular}

Pre $=$ measurements obtained before D-pencillamine therapy. Post $=$ measurements obtained after two years of copper chelation. AST $=$ serum aspartate transaminase. SAP = serum alkaline phosphatase. NS = not significant statistically. (Conversion: bilirubin 17 $\mu \mathrm{mol} / \mathrm{l}=1 \mathrm{mg} / 100 \mathrm{ml}$.) 
Table 2 Copper parameters in intrahepatic cholestasis of childhood during study period

\begin{tabular}{|c|c|c|c|c|c|c|c|}
\hline \multirow[b]{2}{*}{ Patient } & \multicolumn{2}{|c|}{$\begin{array}{l}\text { Plasma } \\
\text { copper } \\
(\mu \mathrm{mol} / \mathrm{l})\end{array}$} & \multicolumn{2}{|c|}{$\begin{array}{l}\text { Plasma } \\
\text { caerulo- } \\
\text { plasmin } \\
(\mathrm{g} / \mathrm{l})\end{array}$} & \multicolumn{3}{|c|}{$\begin{array}{l}\text { 24h urine } \\
\text { copper } \\
\text { ( } \mu \text { mol/d) }\end{array}$} \\
\hline & Pre & Post & Pre & Post & Pre & Initial & Post \\
\hline 1 & $23 \cdot 7$ & $27 \cdot 2$ & 0.42 & 0.51 & - & - & - \\
\hline 2 & 22.6 & $27 \cdot 3$ & 0.40 & 0.45 & 0.8 & 1.9 & 10.7 \\
\hline 3 & 33.0 & $30 \cdot 1$ & 0.33 & 0.57 & 0.8 & 1.2 & 1.9 \\
\hline 4 & $27 \cdot 8$ & $22 \cdot 8$ & 0.51 & 0.41 & 1.5 & $4 \cdot 1$ & $2 \cdot 2$ \\
\hline 5 & 28.7 & $12 \cdot 4$ & 0.51 & 0.31 & $1 \cdot 1$ & 6.4 & $5 \cdot 4$ \\
\hline 6 & $27 \cdot 2$ & $40 \cdot 8$ & 0.53 & 0.68 & $1 \cdot 3$ & 3.4 & $6 \cdot 4$ \\
\hline 7 & $26 \cdot 7$ & $24 \cdot 2$ & 0.43 & 0.3 & $0 \cdot 2$ & 1.0 & 0.7 \\
\hline 8 & $18 \cdot 5$ & - & 0.32 & - & 1.2 & $3 \cdot 2$ & - \\
\hline p value & \multicolumn{2}{|c|}{ NS } & \multicolumn{2}{|c|}{ NS } & \multicolumn{3}{|c|}{$\begin{array}{r}0.01<\mathrm{p}<0.025 \\
0.05<\mathrm{p}<0.1\end{array}$} \\
\hline Normal range & \multicolumn{2}{|c|}{ e $15-22$} & \multicolumn{2}{|c|}{$0.25-0.4$} & & $<0.8$ & \\
\hline
\end{tabular}

Pre $=$ values obtained before $D$-penicillamine therapy.

Initial $=$ mean of three consecutive 24 hour urinary copper

excretions after initiation of D-pencillamine therapy.

Post $=$ values obtained in the study after two years' copper chelation. NS = not significant statistically. (Conversion: copper $63.5 \mu \mathrm{g}=1 \mu \mathrm{mol}$.)

\section{$\mathrm{C}_{1 \mathrm{~g}}$ BINDING}

After treatment, $\mathrm{C}_{1 \mathrm{q}}$ binding increased in five patients of whom three had normal levels before treatment $(0.05<\mathrm{p}<0.1)$ (Table 1$)$.

\section{Histological assessment}

In all patients liver sections were assessed before, during, and after two years of treatment (Table 3). After copper chelation therapy there was no improvement in the liver sections and all histological features of necrosis, fibrosis, or bile staining appeared more obvious at the end of the study despite marked reductions in hepatic copper levels. Semi-quantitative assessment of copper and copper associated protein by histochemical staining was not altered by effective copper chelation with one exception. In this patient, who died with liver failure after repeated gastrointestinal haemorrhages, these histochemical stains suggested increased amounts of both copper and copper associated protein despite significant reductions in hepatic copper levels.

\section{Discussion}

Hepatic copper levels are increased in intrahepatic cholestasis of childhood from an early age, as in Wilson's disease, but there are several features which distinguish abnormal copper metabolism of this type of cholestasis from that of Wilson's disease. ${ }^{15}$ This study provides information on the role of copper chelation therapy in intrahepatic
IHCC LIVER COPPER

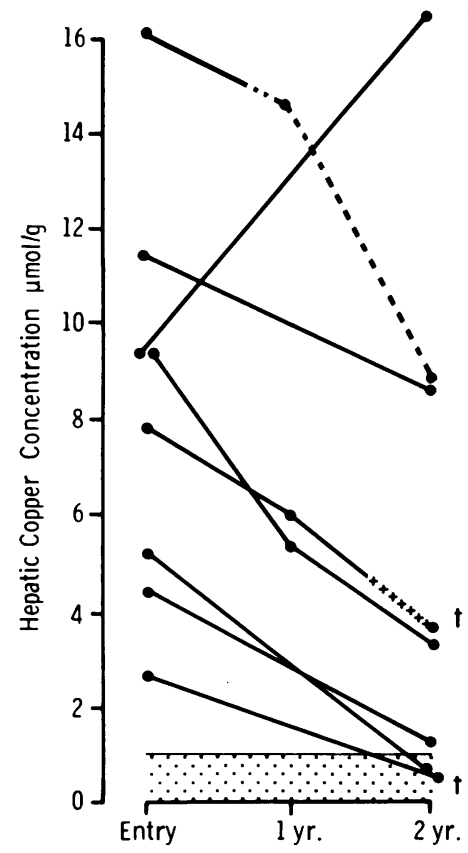

Figure Effect of copper chelation therapy on hepatic copper levels in IHCC $(0 \cdot 05<p<0 \cdot 1)$. Dotted area represents normal hepatic copper values. Solid lines represent period of D-penicillamine therapy. Dashed line represents period of triethylenetetramine dihydrochloride treatment. Crosses represent period of absent copper chelation in a patient before death. Daggers refer to patients' deaths. (Conversion: copper $63.5 \mu \mathrm{g}=1 \mu \mathrm{mol}$.)

Table 3 Histological features in intrahepatic cholestasis of childhood after copper chelation $(n=8)$

\begin{tabular}{lrr}
\hline Feature & Initial & \multicolumn{1}{c}{2 years } \\
\hline Necrosis & $+(4)$ & $+(2)$ \\
& $++(4)$ & $++(6)$ \\
Fibrosis & $+++(0)$ & $+++(0)$ \\
& $+(4)$ & $+(0)$ \\
Bile & $++(4)$ & $++(8)$ \\
& $+++(0)$ & $+++(0)$ \\
Bile ducts & $+(5)$ & $+(5)$ \\
& $++(0)$ & $++(3)$ \\
& $+++(0)$ & $++(0)$ \\
& $0(4)$ & $\downarrow(5)$ \\
\end{tabular}

Histological features of necrosis, fibrosis, bile in intrahepatic cholestasis of childhood were semi-quantitatively assessed and graded,,++++++ for mild, moderate, or severe changes. Total amount of fibrosis surrounding and involving hepatic nodules was estimated after viewing several sections. In each biopsy 12 portal tracts were viewed and bile ducts counted. Bile duct paucity was considered if there were less than four bile ducts counted in 12 portal tracts and scored $(\downarrow)$. No bile ducts in 12 portal tracts were scored (0). 
cholestasis of childhood with increased liver copper concentrations.

Intrahepatic cholestasis of childhood is a rare syndrome and the small number of patients did not allow a control group. Thus, the data from the study have been interpreted carefully. A historical control group was not included because the severity of the disorder varies from patient to patient and may result from several aetiologies. Did the results from this study support a view that increased liver copper concentrations are an important factor in liver damage in intrahepatic cholestasis of childhood? The major reductions in hepatic copper concentrations appeared to be without benefit - that is, there was no symptomatic improvement, a spurt in height and weight were not observed, and liver damage progressed. Also, in an earlier report, markedly increased hepatic copper levels were observed in three patients with intrahepatic cholestasis of childhood (before chelation therapy) over periods ranging from 2.3 years to 6.5 years without evidence of deteriorating liver cell function. ${ }^{15}$ This study appears to support the second possibility that progressive liver damage was independent of liver copper concentration. One patient, with evidence of deteriorating liver cell function, died from a massive gastrointestinal haemorrhage and liver copper concentration before death was normal. A rise in plasma aspartate transaminase and bilirubin levels occurred in one patient, while a marked reduction in liver copper values occurred with D-penicillamine therapy.

Under physiological conditions hepatic copper levels are predominantly maintained by excretion of copper into bile. ${ }^{10}$ The mechanism/s whereby copper chelation treatment reduced hepatic copper concentrations in intrahepatic cholestasis of childhood was not studied directly. Plasma alkaline phosphatase and fasting bile acids, indices of cholestasis, were not significantly altered by treatment. Thus it would appear that chelation therapy did not affect cholestasis and liver copper content was reduced by other mechanisms.

Recently, D-penicillamine has affected histological and biochemical improvement in primary biliary cirrhosis. ${ }^{1018} 31$ The mechanism of this beneficial effect is uncertain and may be related to copper chelation or an immunological effect (as measured by reduced $\mathrm{C}_{1 \mathrm{q}}$ levels). Does this study in intrahepatic cholestasis of childhood, a nonimmunological chronic cholestasis disorder of childhood, add comment on the D-penicillamine effect in primary biliary cirrhosis? Despite effective copper chelation with D-penicillamine in intrahepatic cholestasis of childhood liver damage progressed and levels of $\mathrm{C}_{1 \mathrm{q}}$ binding increased.
Thus, the eneficial effect of D-penicillamine in primary biliary cirrhosis may be independent of copper chelation.

In intrahepatic cholestasis of childhood 24 hour urinary copper excretion (before treatment) was increased but the values observed were less than those in Wilson's disease ${ }^{32}$ or primary biliary cirrhosis. ${ }^{11}$ D-penicillamine increased 24 hour urinary copper excretion about two to four times the pretreatment value in most children with intrahepatic cholestasis of childhood. This response of urinary copper excretion cannot be compared with patients with Wilson's disease ${ }^{23}$ or primary biliary cirrhosis. ${ }^{11}$ The dose of D-penicillamine given to patients with Wilson's disease is usually greater than $1.0 \mathrm{~g}$ dose and therapy generally begins with the full maintenance dose, while patients with primary biliary cirrhosis often achieve a $1.0 \mathrm{~g}$ dose of D-penicillamine after six weeks. After two years of copper chelation urinary copper excretion was increased but less than at the outset, probably reflecting a diminished size of the available copper pool. A similar decrease of urinary copper excretion with time has been observed after treatment of patients with Wilson's disease ${ }^{33}$ and primary biliary cirrhosis. ${ }^{11}$

Despite increased urinary copper excretion in all patients with D-penicillamine, hepatic copper concentration increased in one patient in the study. This increase in hepatic copper concentration was marked. The explanation for this massive increase is not clear. The increase was greater than accumulation of hepatic copper content with time $e^{15}$ and may be related to several factors including metal contamination of liver biopsy material; deepening cholestasis (not apparent); or an effect of Dpenicillamine therapy. Likewise, increased liver copper levels of lesser magnitude have been noted in six of 19 patients with primary biliary cirrhosis treated with D-penicillamine. ${ }^{11}$

This study has shown that both D-penicillamine $(10 \mathrm{mg} / \mathrm{kg} /$ day $)$ and triethylenetetramine dihydrochloride $(20 \mathrm{mg} / \mathrm{kg} /$ day $)$ are effective in reducing hepatic copper levels in intrahepatic cholestasis of childhood. Significant side-effects to Dpenicillamine occurred in two patients, while complications did not develop with triethylenetetramine dihydrochloride. Thus, side-effects to D-penicillamine appear common in intrahepatic cholestasis of childhood, primary biliary cirrhosis, ${ }^{11} 31$ and rheumatoid arthritis ${ }^{34}$ but not in Wilson's disease. This study did not definitely exclude the possibility that increased liver copper concentrations may be toxic to hepatocytes in intrahepatic cholestasis of childhood. Thus, if copper chelation is contemplated in intrahepatic 
cholestasis of childhood with raised liver copper concentrations, triethylenetetramine dihydrochloride, which effectively reduced hepatic copper levels in a patient and did not cause side-effects, should be considered.

Dr J Evans is supported by a Wellcome Research Fellowship. Professor P J Scheuer contributed suggestions to the manuscript and Mr S Pocock advised on statistical analysis. Dr T L Dormandy assayed copper concentrations in plasma and urine. Dr D Flynn advised on interpretation of height and weight percentiles.

\section{References}

1 Evans GW. Copper homeostasis in the mammalian system. Physiol Rev 1973; 53: 535-70.

2 Sass-Kortsak A, Cherniak M, Geiger DW, Slater RJ. Observations on caeruloplasmin in Wilson's disease. $J$ Clin Invest 1959; 38: 1672-82.

3 Cartwright GE, Wintrobe MM. Copper metabolism in normal subjects. Am J Clin Nutr 1964; 14: 224-32.

4 Sternlieb I. Evolution of the hepatic lesion in Wilson's disease (hepatolenticular degeneration). In: Popper $\mathrm{H}$, Schaffner F, eds. Progress in liver diseases. New York: Grune and Stratton, 1972: 511-25.

5 Bearn A. Wilson's disease. In: Stanbury JB, Wyngaarden JB, Frederickson DS, eds. The metabolic basis of inherited disease. New York: McGraw-Hill, 1966: 761-9.

6 Chuttani HK, Gupta PS, Gulati S, Gupta DN. Acute copper sulphate poisoning. Am J Med 1965; 39: 849-54.

7 Todd JR, Gracey JF, Thompson RH. Studies on chronic copper poisoning. I. Toxicity of copper sulphate and copper acetate in sheep. $B r$ Vet $J$ 1962; 11: 482-91.

8 Hunt AH, Parr RM, Taylor DM, Trott NG. Relation between cirrhosis and trace metal content of liver: with special reference to primary biliary cirrhosis and copper. Br Med J 1963; 2: 1498-1501.

9 Worwood M, Taylor DM, Hunt AH. Copper and manganese concentrations in biliary cirrhosis of liver. Br Med J 1968; 3: 344-5.

10 Jain S, Scheuer PJ, Samourian S, McGee JO'D, Sherlock S. A controlled trial of D-penicillamine therapy in primary biliary cirrhosis. Lancet 1977; 1: $831-4$.

11 Deering TB, Dickson ER, Fleming CR, Geall MG, McCall JT, Baggenstoss AH. Effect of D-penicillamine on copper retention in patients with primary biliary cirrhosis. Gastroenterology 1977; 72: 1208-12.

12 Fleming CR, Dickson ER, Baggenstoss AH, McCall JT. Copper and primary biliary cirrhosis. Gastro- enterology 1974; 67: 1182-7.

13 Fleming CR, Dickson ER, Wahner HW, Hollenhorst RW, McCall JT. Pigmented corneal rings in nonWilson liver disease. Gastroenterology 1977; 86: 285-8.

14 Sternlieb I, Harris RC, Scheinberg IH. Le cuivre dans la cirrhose biliaire de l'enfant. Rev Int Hepatol 1966; 16: $1105-10$.

15 Evans JE, Newman S, Sherlock S. Liver copper levels in intrahepatic cholestasis of childhood. Gastroenterology 1978; 75: 875-8.

16 Smallwood RA, Williams HA, Rosenoer VM, Sherlock S. Liver copper levels in liver disease. Studies using neutron activation analysis. Lancet 1968; 2: 1310-13.

17 Tanner MS, Portmann B, Mowat AP et al. Increased hepatic copper concentration in Indian childhood cirrhosis. Lancet 1979; 1: 1203-5.

18 Epstein O, De Villiers D, Jain S, Potter BJ, Thomas HC, Sherlock S. Reduction of immune complexes and immunoglobulins induced by $D$-penicillamine in primary biliary cirrhosis. $N$ Engl J Med 1979; 300: 274-8.

19 Heathcote J, Deodhar KP, Scheuer PJ, Sherlock S. Intrahepatic cholestasis of childhood. $N$ Engl J Med 1976; 295: 801-5.

20 Alagille D, Odievre M, Gautier M, Dommergues JP. Hepatic ductular hypoplasia associated with characteristic facies, vertebral malformations, retarded physical, mental and sexual development, and cardiac murmur. $J$ Pediatr 1975; 86: 63-71.

21 Clayton RJ, Iber FL, Ruebner RJ, McKusick VA. Byler's disease: fatal familial intrahepatic cholestasis in an Amish kindred. $J$ Pediatr 1965; 86: 1025-8.

22 Watson GH, Miller V. Arteriohepatic dysplasia. Familial pulmonary arterial stenosis with neonatal liver disease. Arch Dis Child 1973; 48: 459-66.

23 Walshe JM. Copper chelation in patients with Wilson's disease. A comparison of penicillamine and triethylenetetramine dihydrochloride. $Q J$ Med 1973; 42: 441-52.

24 Murphy GM, Billing BH, Baron DN. A fluorimetric and enzymatic method for estimation of serum total bile acids. J Clin Pathol 1970; 23: 594-8.

25 Zubler RH, Lange G, Lambert PH, Miescher PA. Detection of immune complexes in untreated sera by a modified ${ }^{125} \mathrm{C}_{1 \mathrm{q}}$ binding test: effect of heating on the binding by $\mathrm{C}_{1 \mathrm{q}}$ by immune complexes and application of the test to systemic lupus erythematosis. J Immunol 1976; 116: 232-5.

26 Davies IJT, Musa M, Dormandy TL. Measurements of plasma zinc. J Clin Pathol 1968; 21: 359-65.

27 Todd AP, Thorpe MEC, Rosenoer VM. Tissue copper determinations by neutron activation analysis. J Clin Pathol 1967; 20: 276-9.

28 Lindquist RR. Studies on the pathogenesis of hepatolenticular degeneration. II. Cytochemical methods for the localisation of copper. Arch Pathol 1969; 87: 370-9.

29 Shikata T, Uzawa T, Yoshiwara N, Akatsuka T, Yamazaki S. Staining methods of Australia antigen in paraffin section. Detection of cytoplasmic inclusion bodies. Jap J Exp Med 1974; 44: 25-36.

30 Tanner JM, Whitehouse RH, Takaishi M. Standards 
from birth to maturity for height, weight and height velocity and weight velocity. British children, 1965 Part 2. Arch Dis Child 1966; 41: 613-35.

31 Epstein O, Lee RG, Ross AM, Jain S, Cook DG, Scheuer PJ, Sherlock S. D-penicillamine treatment improves survival in primary biliary cirrhosis. Lancet 1981; 1: 1275-7.

32 Sternlieb I, Scheinberg IH. Prevention of Wilson's disease in asymptomatic patients. $N$ Engl J Med 1968;
278: 352-9.

33 Goldstein NP, Randall RV, Gross JB, Tanxe WN, McCall JT. Wilson's disease (hepatolenticular degeneration). Treatment with $D$-penicillamine and changes in hepatic trapping of radioactive copper. Arch Neurol 1971; 24: 391-400.

34 Day AT, Golding JR, Lee PN, Butterworth AD. Penicillamine in rheumatoid disease: a long-term study. Br Med J 1974; 1: 180-3. 